грешности, допустимые при измерении, некорректный выбор самого метода измерения, способа и т. д. К основным объектам стандартизации СТК можно отнести следующие: общие положения, методику измерений, универсальные и специальные технические средства, организацию и управление данными процессами. Для обеспечения данного процесса необходимо применение стандартов к терминам, классификации технических средств, к контрольным приспособлениям и оборудованию, средствам механизации, к автоматизированным процессам технического контроля, а также к дополнительному оборудованию, инструменту, материалам.

E. Malkova, V. Kulnevich, N. Oleinik

\title{
STANDARDIZATION FOR TECHNICAL CONTROL OF TECHNOLOGICAL PROCESSES IN AGRICULTURAL ENGINEERING
}

Key words: standardization; technical control; destructive test; technological process.

\section{Authors' personal details}

1. Elena Malkova, Candidate of Pedagogical Sciences, Associate Professor, Associate Professor of the Department of Technical Service of Machines, Equipment and Life Safety, South Ural State Agrarian University, 454080, Chelyabinsk, Lenin Ave., 75, phone: +7 (351) 265-56-08, e-mail: lena_v_m@mail.ru.

2. Vera Kulnevich, Candidate of Technical Sciences, Associate Professor, Associate Professor of the Department of Technical Service of Machines, Equipment and Life Safety, South Ural State Agrarian University, 75 Lenin Ave., Chelyabinsk, phone: +7 (351) 265-56-08, e-mail: vera_b_k@mail.ru.

3. Nadezhda Oleinik, Candidate of Pedagogical Sciences, Associate Professor, Associate Professor of the Department of Technical Service of Machines, Equipment and Life Safety, South Ural State Agrarian University, 454080, Chelyabinsk, Lenin Ave., 75, phone: +7 (351) 265-56-08, e-mail: oleynik1010@mail.ru.

The control tools and performers of metrological works that interact with the objects of control according to the established normative documents are the technical control system (TCS). The structure of the TCS consists of: control objects; control processes; technical equipment that takes into account the methods and means of control; control methods; as well as the performers of metrological works themselves. In the process of performing technical control, the measurement procedure is very specific if a certain method is observed. The process is influenced by many factors such as processing operations, various organization systems, production management, and regulatory process documentation. TCS performs its functions according to the established norms, rules, technological documentation for control, it is designed taking into account the requirements of various design, techno-

(C) Малькова Е.В., Кульневич В.Б., Олейник Н.И. logical, production, and other regulatory documents. In the process of manufacturing parts during the technological process, factors of random and systematic errors should be taken into account. These include the following: heterogeneity of the material structure; error in the shape of the workpiece; deviation from the norm of the technological system as a whole; errors allowed during measurement, incorrect choice of the measurement method, method, etc. The main objects of TCS standardization are: general provisions, measurement methodology, universal and special technical means, organization and management of these processes. To ensure this process, it is necessary to apply standards for terms, classification of technical means, for control devices and equipment, for means of mechanization, for automated technical control processes, as well as for additional equipment, tools, and materials.

УДК 621.791.011

DOI: $10.31563 / 1684-7628-2020-54-2-94-100$

Р.Ф. Масягутов, М.З. Нафиков, И.И. Загиров

\section{НОВАЯ ПРИСАДКА ДЛЯ ЭЛЕКТРОКОНТАКТНОЙ ПРИВАРКИ}

Ключевые слова: электроконтактная приварка; присадочная лента; перфорация; пластическая деформация; прочность приварки. 
Введение. Основанные на методе шовной сварки электроконтактные способы восстановления (ЭКП) нашли широкое применение при восстановлении и упрочнении изношенных деталей используемой в АПК техники из-за их несомненных достоинств и преимуществ. Эти способы производительны и позволяют формировать тонкие, малогребнистые, термомеханически упрочненные металлопокрытия. Припуски на последующую механическую обработку деталей составляют порядка $0,25 \ldots$ 0,30 мм на сторону. При способах ЭКП могут применяться различные формы присадочных материалов: стальные проволоки, ленты, металлические порошки, тканые металлические сетки, а также их разнообразные комбинации (сочетания) $[1,2]$.

Наряду с отмеченными достоинствами каждая из перечисленных присадок имеет и недостатки, часто существенные, затрудняющие их использование в ремонтной отрасли.

При электроконтактном напекании металлических порошков значительная доля дорогостоящей присадки просыпается или же смывается водой. Толщина формируемого покрытия по этой причине не поддается регулированию. Само покрытие получается пористым, в нем формируются значительные растягивающие остаточные напряжения, что снижает усталостную прочность восстановленных валов [3, 4].

Стальные проволоки прочно привариваются в твердой фазе к изношенной поверхности детали не при любых, а лишь при рациональных режимах ЭКП. Брак в виде непровара выявить на ранней стадии трудно. Из-за малой площадки контакта между проволокой и инструментом медный ролик-электрод быстро изнашивается в форме кольцевой канавки на его рабочей поверхности $[5,6]$.

Стальные тканые сетки дорогие и дефицитные. Толщины формируемого металлопокрытия при этом виде присадки малые, часто недостаточные для устранения износа поверхности детали [7].

Наиболее часто при ЭКП используется присадочный материал в виде плоских стальных лент $[4,8,9]$. С достаточной производительностью процесс приварки такой присадки реализуется на наплавочных установках конструкции ГОСНИТИ.

Но и этот вид присадки имеет серьезные недостатки и поэтому нуждается в совершенствовании. Форма плоской ленты не позволяет ее пластически деформировать сварочным усилием со стороны ролика-электрода. Пластическая деформация стальной ленты при прохождении импульсного тока минимальная, недостаточная для образования сварного соединения в твердой фазе. Не удается прочная приварка стальной ленты и на режимах, обеспечивающих образование в контакте «лента - деталь» небольших размеров сварочной ванны. При таком сварочном режиме основной поток тепла происходит в массивный медный ролик-электрод, а сварная точка, наоборот, смещается от стыка вглубь детали [4].

По перечисленным причинам прочность приварки ленты низкая, в ней формируются крайне неблагоприятные остаточные напряжения и закалочные трещины. Эту технологию ЭКП нельзя рекомендовать для восстановления деталей, эксплуатирующихся при знакопеременных нагрузках.

В Башкирском ГАУ разработана новая присадка для ЭКП на основе стальной ленты [10]. Отличие предлагаемого технического решения от традиционно применяемых при ЭКП плоских присадочных лент заключается в том, что в присадке с целью уменьшения жесткости просверлены сквозные отверстия. Такая перфорированная лента, приварка которой показана на рисунке 1 , пластически деформируется усилием инструмента при прохождении импульса тока. Общеизвестно, что главным условием установления металлических связей соединяемых в твердой фазе металлов является пластическая деформация в сварном стыке $[4,8]$. Поэтому имеются все основания для предположения, что новая присадка позволяет достичь более высокого качества восстановления. Выдвинутая гипотеза нуждается в подтверждении.

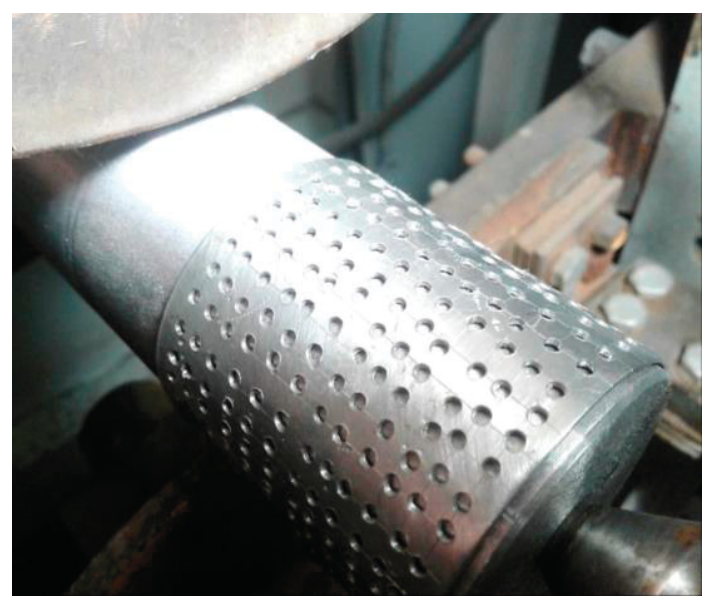

Рисунок 1

Приварка перфорированной стальной ленты на установке 011-1-02 конструкции ГОСНИТИ

Цель исследования - установить и описать математически картину пластической деформации перфорированной присадочной ленты.

Материалы и методы исследования. Методика исследования - теоретическая, основана на положениях теории пластической деформации и горячей обработке металлов давлением. Расчетная схема пластической деформации перфорированной присадочной ленты показана на рисунке 2. 

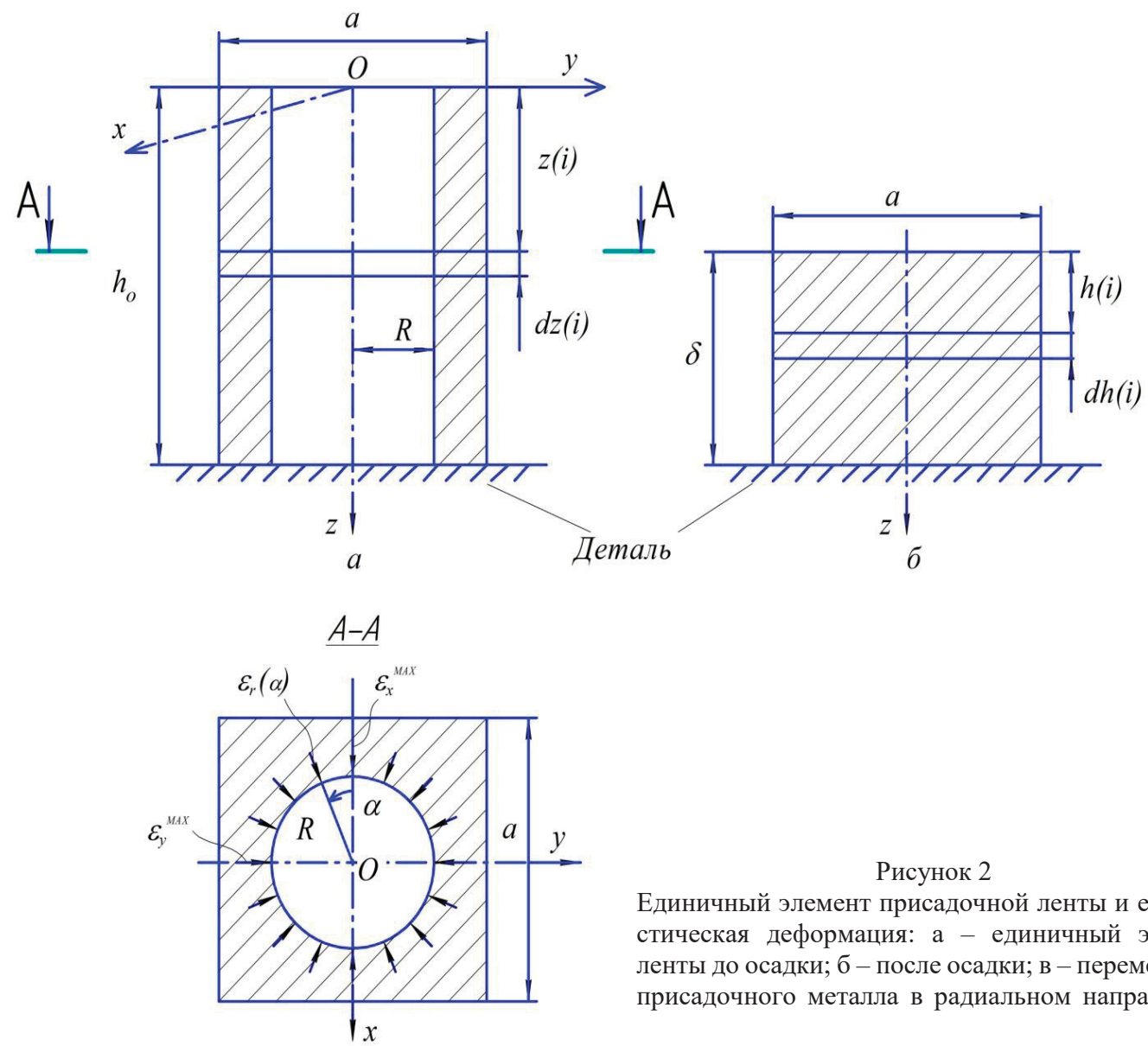

Рисунок 2

Единичный элемент присадочной ленты и его пластическая деформация: а - единичный элемент ленты до осадки; б - после осадки; в - перемещение присадочного металла в радиальном направлении

Изготавливается новая присадка следующим образом. Из холоднокатаной ленты толщиной $h_{0}$ вырезается заготовка, размеры которой соответствуют размерам восстанавливаемой шейки вала. В продольном и поперечном направлениях в ленте с шагом $a$ сверлятся сквозные отверстия радиуса $R$. Поскольку длина и ширина присадки при ее приварке изменяются пренебрежимо мало, то всю ленту можно разбить на повторяющиеся единичные элементы, показанные на рисунке 2 .

До осадки каждый единичный элемент имеет форму прямоугольного параллелепипеда разметами $a \times a \times h_{0}$ с симметричным сквозным отверстием радиуса $R$ (рисунок 2). После осадки элемент принимает форму сплошного прямоугольного параллелепипеда объемом $a \times a \times \delta$, где $\delta$ - толщина формируемого металлопокрытия. Присадочный металл в пластическом состоянии при осадке присадки перемещается к оси отверстия, и при рациональном режиме ЭКП отверстие полностью заплавляется.

В единичном элементе на рисунке 2а выполнено поперечное сечение $A-A$ с координатой $z(i)$ и выделен малый элемент высотой $d z(i)$. После осадки выделенный малый элемент имеет координату $h(i)$ и высоту $d h(i)$ (рисунок 2б). Сечение

$A-A$ изображено на рисунке 2в. В поперечном сечении $A-A$ указан центральный угол $\alpha$.

Единичный элемент перфорированной присадки симметричен относительно осей $O x$ и $O y$, что дает основание считать, что присадочный металл при осадке присадки перемещается от периферии к оси $O z$, т. е. в радиальном направлении, как это показано на рисунке 2в.

Результаты исследования пластической деформачии. Линейную пластическую деформацию оценивали как отношение изменения соответствующего значения размера элемента в результате пластической деформации к его начальному значению.

Приравняв объемы фигур на рисунках $2 \mathrm{a}$ и 26 , вычислим толщину металлопокрытия $\delta$ :

$$
\begin{gathered}
\left(\mathrm{a}^{2}-\pi \times R^{2}\right) \times h_{0}=a^{2} \times \delta ; \\
\delta=\left(1-\pi\left(\frac{R}{a}\right)^{2}\right) \times h_{0} .
\end{gathered}
$$

Введем обозначение $k=R / a$, которое в дальнейшем будем называть коэффициентом перфорации. С учетом безразмерного коэффициента $k$ формула (1) примет окончательный вид

$$
\delta=\left(1-\pi \times k^{2}\right) \times h_{0} .
$$

Аналогично определяем высоту $h(i)$ отсеченной части единичного элемента на рисунке 2б: 


$$
\begin{gathered}
\left(\mathrm{a}^{2}-\pi \times R^{2}\right) \times z(i)=a^{2} \times h(i) ; \\
h(i)=\left(1-\pi \times k^{2}\right) \times z(i) .
\end{gathered}
$$

Вычисляем параметры пластической деформации $\varepsilon_{x}, \varepsilon_{y}$ и $\varepsilon_{z}$ по соответствующим осям координат, а также значение относительной деформации в радиальном направлении $\varepsilon_{z}$.

Дифференцируем выражение (3):

$$
d h(i)=\left(1-\pi \times k^{2}\right) \times d z(i) .
$$

Относительная пластическая деформация по вертикальной оси $O z$ равна:

$$
\varepsilon_{z}(i)=\frac{d h(i)-d z(i)}{d z(i)}=-\pi \times k^{2}=\text { const. }
$$

Пользуемся схемой на рисунке 1в и составляем выражение относительной деформации в радиальном направлении.

Для сечения, определяемого углом $-\pi / 4 \leq \alpha \leq$ $\pi / 4$, искомый параметр равен

$$
\varepsilon_{r}(\alpha)=\frac{\frac{a}{2 \cos \alpha}-\left(\frac{a}{2 \cos \alpha}-R\right)}{\frac{a}{2 \cos \alpha}-R}=\frac{2 k \cdot \cos (\alpha)}{1-2 k \cdot \cos (\alpha)} .
$$

Составляющие радиальной деформации в направлении осей координат $O x$ и $O y$ будут при этом равны:

$$
\begin{aligned}
& \varepsilon_{x}(\alpha)=\varepsilon_{r}(\alpha) \cdot \cos (\alpha)=\frac{k(1+\cos (2 \alpha))}{1-2 k \cdot \cos (\alpha)} ; \\
& \varepsilon_{y}(\alpha)=\varepsilon_{r}(\alpha) \cdot \sin (\alpha)=\frac{k \cdot \sin (2 \alpha)}{1-2 k \cdot \cos (\alpha)} .
\end{aligned}
$$

Из выведенных выражений (1-6) видно, что все рассматриваемые параметры деформации определяются безразмерным геометрическим коэффициентом перфорации $k$, а также они, за исключением $\varepsilon_{z}$, зависят от угла сечения $\alpha$.

На прочность любого формируемого в твердой фазе сварного соединения влияют, прежде всего, деформационные процессы, происходящие в стыке основного и присадочного материалов. В рассматриваемом случае ЭКП прочность приварки практически полностью зависит от параметра радиальной деформации $\varepsilon_{r}(\alpha)$.

Результаты вычислений по выражению (5) приведены в таблице 1 и иллюстрируются графиками на рисунке 3.

Таблица 1 Значения радиальной относительной пластической деформации $\varepsilon_{r}$ в зависимости от коэффициента перфорации $k$ и угла сечения $\alpha$

\begin{tabular}{|c|c|c|c|c|c|c|c|}
\hline$k$ & 0 & 0,1 & 0,2 & 0,25 & 0,3 & 0,4 \\
\hline$\alpha=0$ & 0 & 0,250 & 0,667 & 1,00 & 1,500 & 4,000 & 0,5 \\
\hline$\alpha= \pm \pi / 12$ & 0 & 0,239 & 0,630 & 0,934 & 1,378 & 3,400 & 28,348 \\
\hline$\alpha= \pm \pi / 6$ & 0 & 0,209 & 0,530 & 0,764 & 1,082 & 2,255 & 6,464 \\
\hline$\alpha= \pm \pi / 4$ & 0 & 0,165 & 0,394 & 0,547 & 0,737 & 1,302 & 2,414 \\
\hline
\end{tabular}

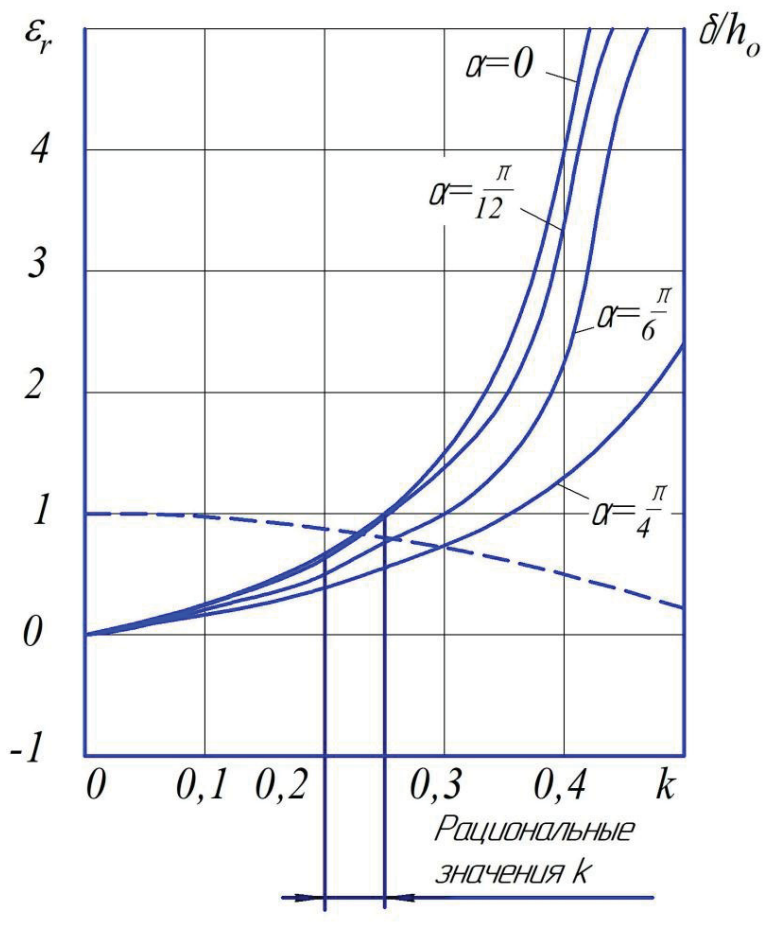

$-\varepsilon_{r} \quad---\delta / h_{o}$

Рисунок 3

К выбору рациональных значений коэффициента перфорации присадочной ленты
Однозначно с позиций увеличения прочности сцепления металлопокрытия с основным металлом целесообразно с минимальным шагом сверлить в присадке отверстия максимально большого радиуса.

Однако при выборе коэффициента перфорации необходимо учитывать и экономический фактор. При перфорировании присадки с большими значениями $k$ увеличиваются потери присадочного металла в стружку.

По формуле (1) для различных значений $k$ вычислены соотношения толщин ленты и формируемого покрытия. График зависимости $\delta / h_{0}$ - $k$ приведен на рисунке 3 .

При выборе рационального значения коэффициента перфорации считаем допустимыми потери присадочного металла ленты в стружку не более 20 \%. Потери присадочного металла не превышают указанного значения при $k \leq 0,25 \ldots 0,30$.

Известно [10], что при аналогичном процессе ЭКП стальных проволок максимально прочное сварное соединение в твердой фазе образуется при относительном удлинении присадки $\varepsilon=0,44 \ldots 0,46$.

С учетом прочности формируемого соединения и экономического фактора окончательно 
выбираем рациональное значение коэффициента $k=0,20 \ldots 0,30$.

При выборе шага перфорации $а$ необходимо учитывать, что приварка присадки на шейку вала производится по винтовой линии с перекрытием сварных швов. В большинстве случаев при ЭКП стальных лент применяется инструмент - ролик-электрод с шириной рабочей части 5...6 мм [7]. Сама приварка присадки производится по перемычкам между отверстиями. Поэтому считаем рациональным значением $a=$ 4...4,5 мм.

Наиболее качественное соединение в твердой фазе образуется в том случае, если химические составы металлов свариваемых деталей совпадают или же различаются незначительно.

Исходная толщина стальной ленты выбирается из условия формирования необходимой толщины металлопокрытия. При таком выборе необходимо учитывать потери присадочного металла в стружку не только при перфорации присадки, но и при последующей механической обработке (обычно шлифованием). Толщина дефектного слоя составляет около 0,25 ...0,30 мм, величины износов шеек практически всех автотракторных валов не превышают 0,20...0,25 мм. С учетом сказанного составлена таблица 2, в которой указаны чистовые толщины слоя металлопокрытия $\delta_{\text {ч }}$ с учетом последующей механической обработки.

Авторы данной работы рекомендуют для восстановления таких деталей использовать холоднокатаные ленты толщиной 0,6 или 0,8 мм.

Дальнейшее направление исследований должно быть направлено на выбор рациональных режимов ЭКП, установление физико-механических свойств покрытия и эксплуатационных испытаний восстановленных деталей.

Таблица 2 Толщины (мм) наносимого металлопокрытия $\delta$ (числитель) и слоя после механической обработки $\delta$ ч (знаменатель) в зависимости от толщины присадочной ленты $h_{0}$ и коэффициента перфорации $k$

\begin{tabular}{|c|c|c|c|c|c|c|c|}
\hline$h_{0}$ & $K=0$ & 0,1 & 0,2 & 0,25 & 0,3 & 0,4 & 0,5 \\
\hline 0,4 & $0,40 / 0,15$ & $0,39 / 0,14$ & $0,35 / 0,10$ & $0,32 / 0,07$ & $0,29 / 0,04$ & $0,20 /-$ & $0,09 /-$ \\
\hline 0,5 & $0,50 / 0,25$ & $0,48 / 0,23$ & $0,44 / 0,19$ & $0,40 / 0,15$ & $0,36 / 0,11$ & $0,25 / 0$ & $0,11 /-$ \\
\hline 0,6 & $0,60 / 0,35$ & $0,58 / 0,33$ & $0,53 / 0,28$ & $0,48 / 0,23$ & $0,43 / 0,18$ & $0,30 / 0,05$ & $0,13 /-$ \\
\hline 0,8 & $0,80 / 0,55$ & $0,78 / 0,53$ & $0,70 / 0,45$ & $0,64 / 0,39$ & $0,57 / 0,32$ & $0,40 / 0,15$ & $0,17 /-$ \\
\hline 1,0 & $1,00 / 0,75$ & $0,97 / 0,72$ & $0,87 / 0,62$ & $0,80 / 0,55$ & $0,72 / 0,47$ & $0,50 / 0,25$ & $0,215 /-$ \\
\hline
\end{tabular}

Выводы. 1. Для повышения качества восстановления изношенных деталей применяемой в АПК техники электроконтактной приваркой стальных лент предлагается производить перфорацию присадки. Эффект применения новой присадки заключается в том, что при ЭКП происходит пластическая деформация, присадочный металл заполняет имеющиеся отверстия в ленте. Относительное движение разогретого металла присадки по восстанавливаемой поверхности разрушает и выносит из стыка плотные гидрооксидные пленки, препятствующие образованию прочных металлических связей в твердой фазе.

2. Введен показатель и термин «коэффициент перфорации $k »-$ отношение радиусов отвер- стий к шагу их сверления. Показано, что присадочный металл испытывает при приварке трехмерную пластическую деформацию, показатели которой зависят, прежде всего, от безразмерного геометрического коэффициента перфорации. Установлены рациональные значения коэффициента $k=0,20 \ldots 0,30$, учитывающие одновременно прочность формируемого в твердой фазе сварного соединения и потери металла ленты при сверлении отверстий.

3. Показано, что для восстановления большинства валов применяемой в АПК техники рациональный шаг перфорации $a$ лент толщиной 0,6-0,8 мм равен 4...4,5 мм.

\section{Библиографический список}

1. Латыпов, Р.А. Электроконтактная приварка. Теория и практика [Текст] / Р.А. Латыпов, В.В. Булычев, П.И. Бурак и др. Курск: Университетская книга. 2016. 392 с.

2. Сайфуллин, Р.Н. Свойства покрытий, полученных электроконтактной приваркой металлических порошков [Текст] / Р.Н. Сайфул- лин, Э.Л. Левин, В.С. Наталенко // Упрочняющие технологии и покрытия. 2014. № 2. С. 38 43.

3. Gabitov I.I., Saifullin R.N., Farhshatov M.N., Negovora A.V., Mudarisov S.G., Khasanov E.R., Galiullin R.R., Gabdrafikov F.Z., Yunusbaev N.M. and Valiev A.R., 2018. Hardening of 
Electrohydraulic Injectors Valve Units of Diesels at Repair. Journal of Engineering and Applied Sciences, 13: 6478-6486.

4. Латыпов, Р.А. Выбор компактных и порошковых металлических материалов и управление качеством покрытий при упрочнении и восстановлении деталей электроконтактной приваркой [Текст]: дис. ... докт. техн. наук: 05.02.01 / Р.А. Латыпов. М., 2007. 323 с.

5. Nafikov M.Z., Zagirov I.I. Examination of the process of wear of a roller electrode in electric resistance surfacing with a wire. J. Welding International, 2007, vol. 21, № 10, p. 757-759.

6. Нафиков, М.3. Определение размеров ролика для электроконтактной наплавки валов [Текст] / М.3. Нафиков, И.И. Загиров, Р.Н. Сайфуллин // Упрочняющие технологии и покрытия. 2007. № 2. С. 21-22.

7. Павлов, А.П. Разработка технологии восстановления деталей электроконтактной приваркой сетчатых присадочных материалов [Текст]: автореф. дис. ... канд. техн. наук: 05.20.03 / А.П. Павлов. Уфа, 2011. 19 с.

8. Фархшатов, М.Н. Ресурсосберегающие технологии восстановления деталей сельскохо- зяйственной техники и оборудования электроконтактной приваркой коррозионностойких и износостойких материалов [Текст]: дис. ... докт. техн. наук / М.Н. Фархшатов. Саранск, 2007. $442 \mathrm{c}$.

9. Сайфуллин, Р.Н. Свойства покрытий, полученных электроконтактной приваркой присадочных материалов из стальных лент [Текст]/ Р.Н. Сайфуллин, М.Н. Фархшатов, Э.Л. Левин, М.3. Нафиков, В.С. Наталенко, Л.Ф. Исламов, К.В. Юферов // Упрочняющие технологии и покрытия. 2014. № 3. С. 13-16.

10. Пат. 2700891 Российская Федерация, МПК В23К 11/06, В23К 35/02. Присадочная лента для электроконтактной приварки [Текст] / М.З. Нафиков, А.Ю. Коннов, Р.Ф. Масягутов; заявитель и патентообладатель федеральное государственное бюджетное образовательное учреждение высшего образования Башкирский государственный аграрный университет. № 201910 7038/02; заявл. 12.03.2019; опубл. 23.09.2019; Бюл. № 27; 5 с.; ил.

11. Нафиков, М.3. Параметры электроконтактной наплавки [Текст] / М.3. Нафиков // Технология металлов. 2005. № 7. С. 29-31.

\section{Сведения об авторах}

1. Масягутов Риваз Фаизович, ассистент кафедры технологии металлов и ремонта машин, ФГБОУ ВО Башкирский ГАУ, 450001, г. Уфа, ул. 50-летия Октября, 34, тел.: +7 (347) 228-07-71, e-mail: rivazm@yandex.ru.

2. Нафиков Марат Закиевич, доктор технических наук, профессор кафедры механики и конструирования машин, ФГБОУ ВО Башкирский ГАУ, 450001, г. Уфа, ул. 50-летия Октября, 34, тел.: +7 (347) 228-07-71, e-mail: nafikovmz@rambler.ru.

3. Загиров Ильнур Илдарович, кандидат технических наук, доцент кафедры механики и конструирования машин, ФГБОУ ВО Башкирский ГАУ, 450001, г. Уфа, ул. 50-летия Октября, 34, тел.: +7 (347) 228-07-71, e-mail: zagirych22@mail.ru.

Эффективными способами восстановления изношенных деталей являются основанные на методе шовной сварки электроконтактные способы (ЭКН). Востребованность таких технологий объясняется их простотой, высоким качеством восстановления, минимальной последующей механической обработкой, благоприятными условиями работы оператора-наплавщика. В качестве присадочных материалов при ЭКН применяют стальные проволоки, тканые сетки, металлические порошки, но наиболее удобным и распространенным видом присадки являются стальные плоские ленты. Более широкое производственное применение способа ЭКП стальных лент сдерживается существенным недостатком присадки - ее жесткостью. Из-за недостаточной пластической деформации присадочный металл слабо приваривается к детали, эксплуатационные характеристики восстанов- ленных валов низкие. Для устранения указанного недостатка в Башкирском ГАУ разработана новая перфорированная присадка на основе стальной ленты. Такая присадка легко осаживается усилием инструмента при прохождении импульса тока, происходит трехмерная пластическая деформация, обеспечивающая максимально прочную приварку покрытия. Раскрыт физический механизм образования прочных металлических связей между присадочным металлом и основным металлом детали. Выполнены аналитические исследования пластической деформации присадочного металла, результаты которых позволяют определить рациональные геометрические параметры новой перфорированной присадки, а именно: исходную толщину ленты, радиус и шаг сверления отверстий, коэффициент перфорации. 


\title{
NEW FILLER FOR ELECTROCONTACT WELDING
}

Key words: electrocontact welding; filler tape; perforation; plastic deformation; welding strength.

\section{Authors' personal details}

1. Rivaz Masyagutov, Assistant, Department of Metal Technology and Machine Repair, Federal State Budgetary Educational Institution of Higher Education «Bashkir State Agrarian University», 450001, Ufa, 50-letiya Oktyabrya str., 34, phone: +7 (347) 228-07-71, e-mail: rivazm@yandex.ru.

2. Marat Nafikov, Doctor of Technical Sciences, Professor, Department of Mechanics and Machine Design, Federal State Budgetary Educational Institution of Higher Education «Bashkir State Agrarian University», 450001, Ufa, 50-letiya Oktyabrya str., 34, phone: +7 (347) 228-07-71, e-mail: nafikovmz@rambler.ru.

3. Ilnur Zagirov, Candidate of Technical Sciences, Associate Professor of the Department of Mechanics and Machine Design, Federal State Budgetary Educational Institution of Higher Education «Bashkir State Agrarian University», 450001, Ufa, 50-letiya Oktyabrya str., 34, phone: +7 (347) 228-07-71, e-mail: zagirych 22@mail.ru.

Effective methods of restoring worn parts are based on the method of seam welding by electrical contact methods (ECM). The demand for such technologies is explained by their simplicity, high quality of restoration, minimal subsequent mechanical processing, and favorable working conditions for the operator-welder. The steel wires, woven nets, metal powders are used as filler materials for ECM, but the most convenient and widespread type of additive is steel flat tapes. A wider industrial application of the ECM for steel tapes is constrained by a significant disadvantage of filler - its rigidity. Due to insufficient plastic deformation, the filler metal is weakly welded to the part, the operational characteristics of the restored shafts are low. To eliminate this drawback, the Bashkir State Agrarian University has developed a new perforated additive based on steel tape. Such an additive is easily deposited by the force of the tool during the passage of a current pulse, three-dimensional plastic deformation occurs, providing the most durable welding of the coating. The physical mechanism of the formation of strong metal bonds between the filler metal and the base metal of the part is disclosed. The analytical studies of the plastic deformation of the filler metal were carried out, the results of which allow us to determine the rational geometric parameters of the new perforated additive, namely: the initial thickness of the tape, the radius and pitch of the holes, the perforation coefficient.

() Масягутов Р.Ф., Нафиков М.З., Загиров И.И.

УДК 62-799

DOI: $10.31563 / 1684-7628-2020-54-2-100-105$

Ш.Ф. Нигматуллин, М.М. Разяпов, С.С. Акимов, Р.Ф. Самиков

\section{РАЗРАБОТКА СТЕНДА ДЛЯ ИСПЫТАНИЯ ПРЕДПУСКОВЫХ ПОДОГРЕВАТЕЛЕЙ СИЛОВЫХ АГРЕГАТОВ СЕЛЬСКОХОЗЯЙСТВЕННОЙ И СТРОИТЕЛЬНОЙ ТЕХНИКИ}

\author{
Ключевые слова: предпусковой подогреватель; стенд; диагностирование; горелка; темпера- \\ тура; термопары; датчик.
}

Введение. При эксплуатации автотракторной техники в условиях минусовых температур всегда имеется риск трудного запуска двигателя и повышенного эксплуатационного износа узлов и агрегатов [1]. Для того чтобы минимизировать такие последствия, применяются различные устройства и агрегаты, которые облегчают запуск двигателя. Самыми распространёнными являются автономные предпусковые подогреватели двигателя [16].
При эксплуатации в период минусовых температур было выявлено, что 60 \% отказов предпусковых подогревателей связано с некачественны топливом, ненадлежащим состоянием электроник, износом резинотехнических изделий, а также выходом из строя составных частей горелки подогревателя [3-5].

Цель исследования: создание рабочей модели стенда и проверка его работоспособности на различных режимах работы предпусковых 